\title{
SOIL ORGANIC MATTER VARIATION OF TOPSOIL UNDER INTENSIVE TILLAGE: THE CASE OF SANHU FARM, HUBEI PROVINCE, CHINA
}

\author{
WANG, L. Y. ${ }^{1}-$ WANG, H. Z. ${ }^{1,2^{*}}-$ PAN, F. J. ${ }^{1}-$ ZHOU, Y. $.^{1,2^{*}}-$ HA, J. ${ }^{3}-$ LI, R. D. ${ }^{4}$ \\ ${ }^{1}$ Key Lab for Geographical Process Analysis \& Simulation of Hubei Province, Faculty of Urban \\ \& Environmental Science, Central China Normal University, Wuhan 430079, China \\ ${ }^{2}$ Center of Land Science Research, Central China Normal University, Wuhan 430079, China \\ ${ }^{3}$ School of Environmental and Sustainability Sciences, Kean University, New Jersey 07083, USA \\ ${ }^{4}$ Institute of Geodesy and Geophysics, Chinese Academy of Sciences, Wuhan 430077, China \\ ${ }^{*}$ Corresponding authors \\ e-mail: wanghongzhi@mail.ccnu.edu.cn,yzhou@mail.ccnu.edu.cn
}

(Received $1^{\text {st }}$ Mar 2019; accepted 21 ${ }^{\text {st }}$ May 2019)

\begin{abstract}
Soil organic matter (SOM) plays an important role both to condition soil properties and to mitigate climate change. SOM change pattern after intensive tillage is still not well revealed. Taking Sanhu Farm, Jiangling County, Hubei Province, China as a case area, based on topsoil survey samples of 1990, 1994 and 2000 respectively, the spatial distribution pattern and temporal change of SOM content was analyzed. The results show that (1) SOM content successively decreased with the increase of land exploitation history; (2) topsoil SOM value of the three survey years showed a similar spatial pattern whereby the highest SOM value was distributed in the center, and SOM value decreased incrementally as the distance from the center increased, which showed the SOM values were negatively correlated to the altitude of study area; (3) there was an overall tendency for the maximum or minimum value of SOM to approach to the average value over time; (4) SOM concentration changes were influenced by crop systems changes related to the price of crops and related policies. The study depicts SOM variability after the reclamation from virgin land to arable land at a landscape scale, which may contribute to research revealing spatial distribution patterns and controlling elements of SOM change.
\end{abstract}

Keywords: land reclamation from lakes, SOM change pattern, land exploitation history, the kriging interpolation, spatial autocorrelation, crop systems

\section{Introduction}

Soil organic matter (SOM) is the largest source of SOC, which is a key element to soil quality for its far reaching effect on soil physical, chemical and biological properties (Laik et al., 2009; Nadi et al., 2017). As an important feature of soil, even in small amounts, organic matter is very important to keep soil healthy (Osman, 2013). It has tremendous biological significance for providing food for microorganisms, storing nutrients, retaining water, and performing as a soil conditioner and aggregating agent (Manlay et al., 2007; Osman, 2013). The Soil surface comprises the largest carbon stock in terrestrial ecosystems, and soils to $1 \mathrm{~m}$ depth contain $74 \%$ of the total terrestrial $\mathrm{C}$ stocks (Lal, 2004; Batjes, 2016; Vitharana et al., 2019). The global soil organic carbon (SOC) pool is estimated to amount to $1200-1600 \mathrm{Pg}$ carbon in the upper $1 \mathrm{~m}$ (Batjes, 1999), representing 2.5 times the carbon pool in vegetation, or 2 times the amount of carbon in the atmosphere. Change of soil organic matter (SOM) content under intensive 
tillage has becomes a pivotal concern in soil research as an option for mitigation of climate change (Schulp et al., 2008b; Das et al., 2008).

Insight in variability of SOM quality and quantity is required to quantify the greenhouse gas mitigation potential of the landscape (Schulp et al., 2008a). Research shows that there is a direct link between SOM content and human impact, observed in land use patterns or land management systems, for example (Smith et al., 2000; Lettens et al., 2005; Abdollahi et al., 2014; Gmach et al., 2018; Wood et al., 2018). SOM contents are generally lower after intensive tillage (Degryze et al., 2004; Lettens et al., 2004a; Gerzabek et al., 2005; Papienik et al., 2007), especially the surface soil organic carbon and total nitrogen contents in cultivated areas (Schulp et al., 2008b; Barrett et al., 2015; Wood et al., 2018). Afforestation by different plantations increased soil C pools to different magnitudes (Laik et al., 2009; Kukuls et al., 2019). Alternative management systems, like reduced tillage or organic farming, have been introduced that are considered to lead to more sustainable land use and increased sequestration of atmospheric C into agricultural soils (Pulleman et al., 2000). However Dutch research highlights some relationships between the SOM content variability and land condition before its exploitation. It is not a universal rule to lower SOM contents after intensive tillage (Webb, 1998; Schulp et al., 2008b; Abdullah, 2014).

At landscape scale, patterns of management, land use or land use history might better present the spatial variability of SOM pools (Veldkamp et al., 2001; Dendoncker et al., 2004; Schulp et al., 2008b) while soil and groundwater may dominate over other factors that influence SOM pools (quality and quantity) at a national scale. At temporal scales up to a few decades, SOM content changes are observed following land use conversions (Lettens et al., 2004b; Falloon et al., 2006; Gmach et al., 2018). Intensive cultivation is often exerted to land in China to support the large population. Soil pedons and characteristics including SOM contents are quite different to the natural ones under the Chinese special management patterns.

In this paper, we will try to reveal how the SOM contents have been changed under intensive tillage at landscape scale, using Sanhu Farm as a case study area, which belongs to Jiangling County, Hubei province, China. This site has been reclaimed farmland from a lake since 1960 and is currently dominated by anthrosols (Wang et al., 2010).

\section{Materials and Methods}

\section{Case study area}

Sanhu Farm $\left(30^{\circ} 10^{\prime}-30^{\circ} 16^{\prime} \mathrm{N}, 112^{\circ} 29^{\prime}-112^{\circ} 35^{\prime} \mathrm{E}\right)$ is located in southeast of Jiangling County, Hubei province in central China, with an area of $63.5 \mathrm{~km}^{2}$ (Fig. 1). There are 14,812 people in Sanhu Farm and 55.49\% of them are peasants. The percentage of forest cover is only $1.92 \%$. The max distance from north to south inside the farm is $11.2 \mathrm{~km}$ while from east to west is $7.75 \mathrm{~km}$. The area is characterized by a subtropical humid monsoonal climate. The average monthly temperature reaches a maximum of $27.2^{\circ} \mathrm{C}$ in July and a minimum of $3.5^{\circ} \mathrm{C}$ in January. The average annual temperature is $16.1^{\circ} \mathrm{C}$ and the average annual precipitation is about $1100 \mathrm{~mm}$. The altitude of Sanhu Farm ranges from $25.1 \mathrm{~m}$ to $29.3 \mathrm{~m}$, with an average altitude of $25.8 \mathrm{~m}$ (Yellow Sea Height System). The relief of the farm is like a shallow dish, a little lower at the center and higher at the surrounding boundary. At the same time, it tilts 
southwardly with a slope of about one five-thousandth. The parent soil material of Sanhu Farm is Quaternary sediments of fluvial or lacustrine deposits.

Sanhu Farm was once one of the Four Lakes in Jianghan Plain. Jianghan Plain is located in the middle reach of the Yangtze River basin where the Han River meets the Yangtze. This part of the basin was formed mainly by the alluviation and deposition of sediment from these two rivers. Jianghan Plain is one of the most important commodity grain and oil production bases of China and it is distinguished by its numerous shallow lakes. There were 1,141 lakes during the 1960s, but this number was reduced to 752 lakes in 1990s. There is a Four-Lake Area in Jianghan Plain, which named for the four biggest lakes of Jianghan Plain, one of which was Sanhu Lake which no longer exists (only two larger lakes remain of the original four). Sanhu Farm was named after Sanhu Lake.

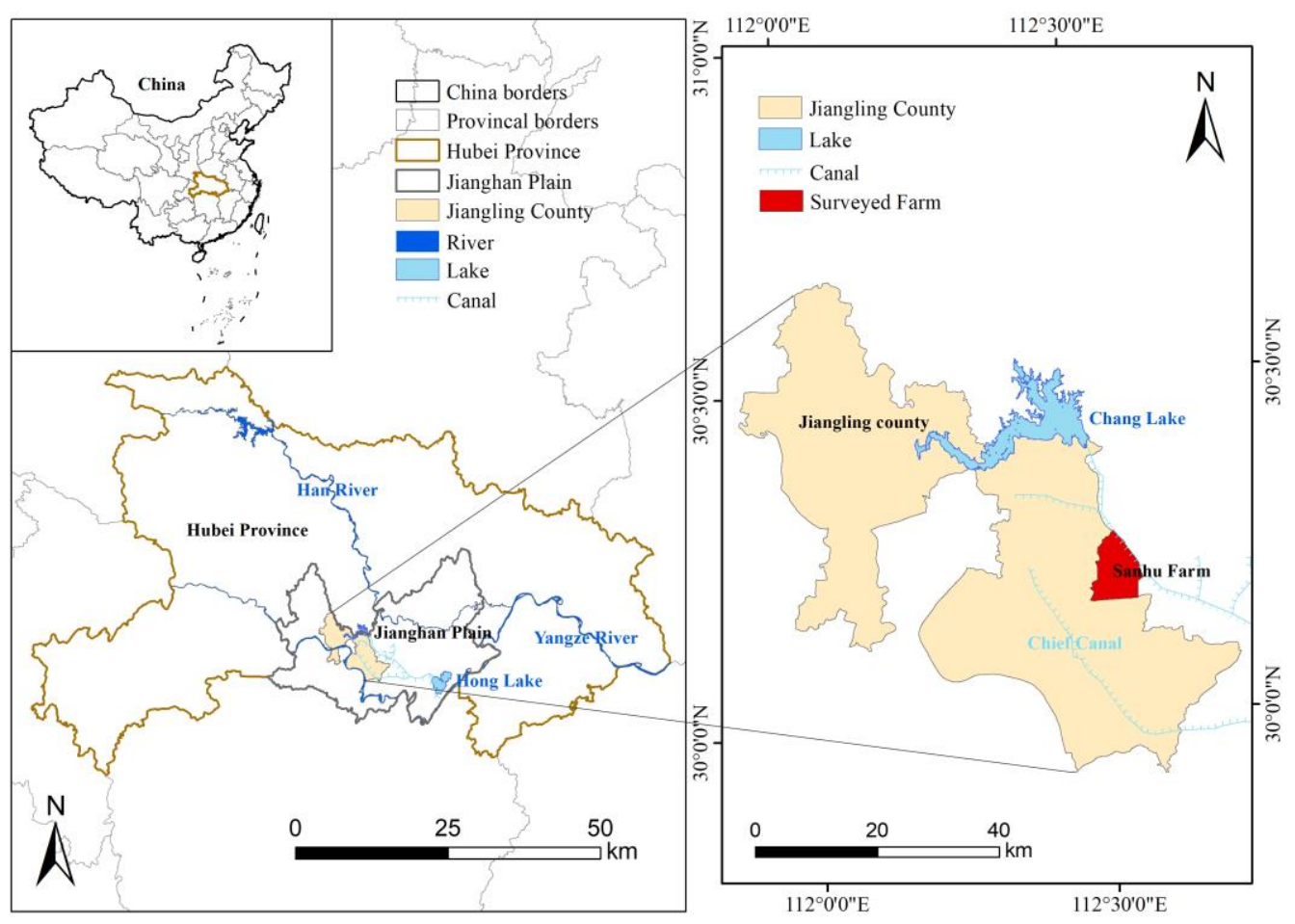

Figure 1. Location of Sanhu Farm

The plan of reclamation of Sanhu Lake began from 1960 just after the fulfillment of the construction of the Chief Canal of the Four Lake Area. There were two main objectives of the reclamation of Sanhu Farm. Firstly, there was a famine nationwide in China from 1958 to the early 1960s, and relieving the food problem was of utmost importance at that time. Secondly, many people were suffering from schistosome, a disease develops in the slack water environments. The reclamation of Sanhu Lake effectively addressed both of these concerns.

The Sanhu Lake area went through three land reclamation periods before reaching its present pattern. In the first stage, from 1962 to 1965 , there were $33 \mathrm{~km}^{2}$ of cultivated land reclaimed. In the second stage, from 1971 to $1973,16.5 \mathrm{~km}^{2}$ were reclaimed. In the third stage, from 1975 to $1979,14 \mathrm{~km}^{2}$ were reclaimed. By the end of 1979, the present pattern of Sanhu Farm had been formed. 
Three sides of Sanhu Farm is bound by water bodies, that is, Chief Canal of FourLake Area $(8.6 \mathrm{~km})$ on the east, Cengda River on the south and Cenhe River on the west. There is a well-developed water drainage system in Sanhu Farm, consisting of 7 main canals, 28 sub-canals and hundreds of ditches, which is connected or controlled by culverts and Watergates Developed Artificial Water Systems: numerous canals and ditches (Fig. 2). The water drainage system has been efficient to drain logged water to the outside canals and to irrigate the farmland, as well. So the area maintains the outline of Sanhu Lake.

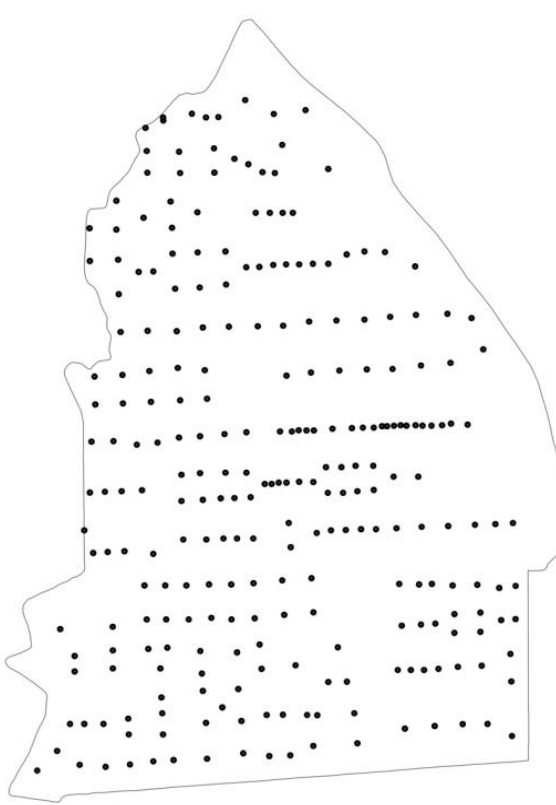

(a) Topsoil Samples

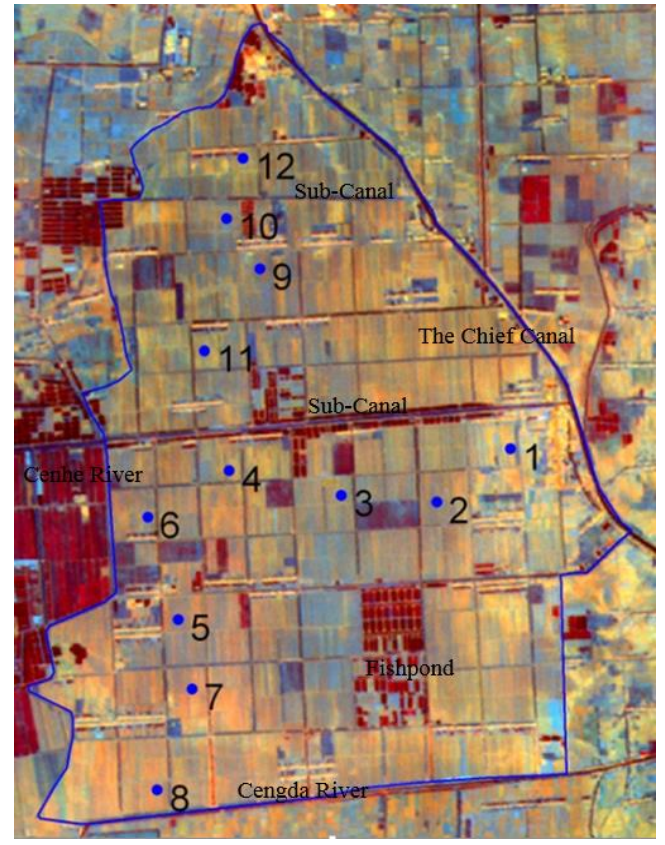

(b) Soil Profiles

Figure 2. Distribution Map of Topsoil Samples (a) or Soil Profiles (b)

Before 1994, the main crop in Sanhu Farm was rice because of the enacting of the national policy "Food for the Program", due to the national famine from the late 1950s to the early 1960s. After 1994, most of the paddy land was changed to dry crops which were harvested twice per year (cotton and rapeseed, respectively). However, the area of paddy has been expanding again as a result of the National Commissariat Allowance Policy from 2004 and the rising price of rice (Wang et al., 2010), but the speed of expansion has been restricted due to the degradation of the local drainage system. As a result, it is necessary to study the variation of SOM caused by the fluctuation of land use and management and to evaluate the impact of land use change on soil properties and climate change at a landscape scale.

\section{Data collection and processing}

\section{Soil samples processing and analyzing}

Some temporal and typological data were sampled and collected, including soil survey data of topsoil random samples without spatial information from both 1980 (643 samples) and 1987 (516 samples), soil survey data of topsoil with spatial information of 
262 random samples from 1990, 1994 and 2000, and soil horizontal sampling analysis data of 12 profiles from 2008 which have spatial points corresponding to former data.

Soil samples collection and pre-treatment were all carried out from October to November just after the harvest of rice in order to keep the seasonal consistency of the soil samples. Every topsoil sampling data was a mixture of arable horizon. 12 soil profiles $(1.0 \mathrm{~m}$ wide $\times 0.8 \mathrm{~m}$ thick $\times 1.1 \mathrm{~m}$ deep) were dug at locations shown in Fig. 2 . The geographic coordinates of every profile were recorded by GPS as well as photos of the landscape where the soil profiles were taken. Samples from every soil horizon in each profile were collected using a cutting ring. All soil samples were put in sterilized Kraft paper sacks with plastic bags outside to prevent water volatilization and were transported to a laboratory and kept at lower temperature. Samples were allowed to air dry and passed through a $1 \mathrm{~mm}$ bore diameter sieve first. One-fourth volume of every soil sample was collected for chemical analysis after passing through a $0.1 \mathrm{~mm}$ bore diameter sieve. The external heating method $\left(\mathrm{K}_{2} \mathrm{Cr}_{2} \mathrm{O}_{7}\right.$ at $\left.0.4 \mathrm{~mol} / \mathrm{L}-\mathrm{H}_{2} \mathrm{SO}_{4}\right)$ was used to determine the SOM content of all samples in the laboratory (Walkley and Black, 1934; Mirzaee et al., 2016; Singh et al., 2019).

\section{Geographical data collection and data spatialization}

A GIS based database of the study area was constructed containing a DEM of 1:10000 (1980), soil survey data of topsoil, and soil horizontal sampling data of several profiles and tables of soil survey data. The spatial system of the database is the Xi'an Geodetic Coordinate System 1980, Gauss-Krueger Projection. All the soil survey data with spatial information were digitalized in the format of DBF. According to the spatial information of the geographic coordinates of topsoil samples or soil profiles, the DBF data were converted to the point layer of the distribution of topsoil samples (Fig. 2a) or soil profiles (Fig. 2b) where the background is a TM image of May, 2005.

\section{The kriging interpolation for the SOM spatial-temporal pattern prediction}

There were 262 topsoil point observations from 1990, 1994 and 2000 which had exactly location information corresponding to the three different years. A DBF file of SOM content of 262 topsoil samples of the three years was connected to the point layer of the distribution of topsoil samples respectively under the ArcGIS10 platform environment. Then the Kriging interpolation technique was applied to depict the spatial pattern of SOM of the three years. The Kriging interpolation method is based on geostatistical models that include autocorrelation-that is the statistical relationships among the measured points. Kriging is a multistep process, includes exploratory statistical analysis of the data, variogram modeling, creating the surface, and (optionally) exploring a variance surface. The first step for the Kriging interpolation is to select the best fitted model which standardizes the mean near to zero, makes the Root-Mean-Square as small as possible, makes the average Standard Error near to the Root-Mean-Square, and standardizes the Root-Mean-Square Standardized near to one. Considering factors of error covariance analysis of every model type synthetically, the Exponential model best fits to identify the SOM for 1990 and the Spherical model best fits to identify the SOM for 1994 and 2000. 


\section{Results and analysis}

\section{The total trend of SOM concentration change}

The average SOM concentration of every survey year was calculated by Excel according to all the topsoil random samples (Table 1). Table 1 shows that the mean SOM concentration decreased from 1980 to 2008 with an average decrease rate of $1.01 \mathrm{~g} / \mathrm{kg}$ per year. At the earliest stage, the SOM concentration decreased rapidly with a highest average yearly decrease rate of $2.57 \mathrm{~g} / \mathrm{kg}$. At the following stages, the mean yearly SOM decrease rate fluctuated under $0.78 \mathrm{~g} / \mathrm{kg}$. It tells us the SOM concentration successively decreased with the increase of the exploitation history.

Table 1. The average concentration of SOM (Unit:g/ $\mathrm{kg}$ )

\begin{tabular}{c|c|c|c|c|c|c|c}
\hline Year & $\mathbf{1 9 8 0}$ & $\mathbf{1 9 8 7}$ & $\mathbf{1 9 9 0}$ & $\mathbf{1 9 9 4}$ & $\mathbf{2 0 0 0}$ & $\mathbf{2 0 0 8}$ & Total \\
\hline Types of Samples & topsoil & topsoil & topsoil & topsoil & topsoil & profile & \\
Spatial Located? & no & no & Yes & Yes & Yes & Yes & \\
Number of Samples & 643 & 516 & 262 & 262 & 262 & 12 & \\
SOM of topsoil & 54.0 & 36.0 & 35.4 & 32.9 & 29.4 & 25.6 & \multirow{2}{*}{ Annual decrease rate } \\
Anno. & $/$ & 2.57 & 0.20 & 0.63 & 0.58 & 0.78 & 1.01 \\
\hline
\end{tabular}

The samples of 1990, 1994 and 2000 were co-located in the three survey years, so the data may show more objective information. The annual decrease rate of SOM content was $0.63 \mathrm{~g} / \mathrm{kg}$ from 1990 to 1994 , and $0.58 \mathrm{~g} / \mathrm{kg}$ from 1994 to 2000. The decrease of the former period was more rapid than that of the later period. The value of SOM greatly affects the soil productivity. Usually the SOM concentration value can be divided into three main grades as POOR, MEDIUM and ABUNDANT. When the SOM concentration value falls between 20-40 g/kg, it is MEDIUM; below $20 \mathrm{~g} / \mathrm{kg}$, POOR; above $40 \mathrm{~g} / \mathrm{kg}$, ABUNDANT. Sample numbers and percentages of every SOM concentration grade of the three survey years are shown in Table 2.

Table 2. Sample numbers and percentage of every SOM concentration grade

\begin{tabular}{c|c|c|c|c|c|c}
\hline Year & \multicolumn{3}{|c|}{ Sample Numbers } & \multicolumn{3}{c}{ Sample Number Percentage } \\
\hline \multirow{2}{*}{ Grade } & $<20 \mathrm{~g} / \mathrm{kg}$ & {$[20-40 \mathrm{~g} / \mathrm{kg}]$} & $>40 \mathrm{~g} / \mathrm{kg}$ & $<20 \mathrm{~g} / \mathrm{kg}$ & {$[20-40 \mathrm{~g} / \mathrm{kg}]$} & $>40 \mathrm{~g} / \mathrm{kg}$ \\
& Poor & Medium & Abundant & Poor & Medium & Abundant \\
1990 & 32 & 155 & 75 & 12.2 & 59.2 & 28.6 \\
1994 & 46 & 143 & 73 & 17.6 & 54.6 & 27.9 \\
2000 & 19 & 193 & 51 & 7.3 & 73.7 & 19.5 \\
\hline
\end{tabular}

Among the 262 samples, there are 75 samples graded as ABUNDANT in 1990, 73 samples in 1994, but only 51 samples in 2000; The percentage of samples graded as ABUNDANT decreased from $28.6 \%$ in 1990 to $19.5 \%$ in 2000. In the other end, there are 32 samples graded as POOR in 1990, 46 samples in 1994, but only 19 samples in 2000 (Table 2). In the long run, the SOM concentration differences of samples decreased after the land reclamation and intensive tillage.

\section{The prediction of SOM spatial patterns and analysis}

The distribution maps of the topsoil organic matter of the three survey years were depicted (Fig. 3) through the Kriging interpolation based on the topsoil sampling point 
distribution layer under ArcGIS 10.1 platform with selected appropriate models (Table 3), and with 10 classes divided by Natural Breaks rule with a slight artificial interference. The maps (Fig. 3) show us that there was a high SOM center located in the south-middle part of the study area running through all the three survey years. In 1990, the SOM values decrease incrementally as the distance from the high SOM center increases. Compared with 1990, the highest SOM region of 1994 shrank considerably. By 2000, the highest SOM region divided into two centers, and the top two SOM classes (Legend) no longer existed, which were component classes of the SOM distribution maps of the former two survey years.

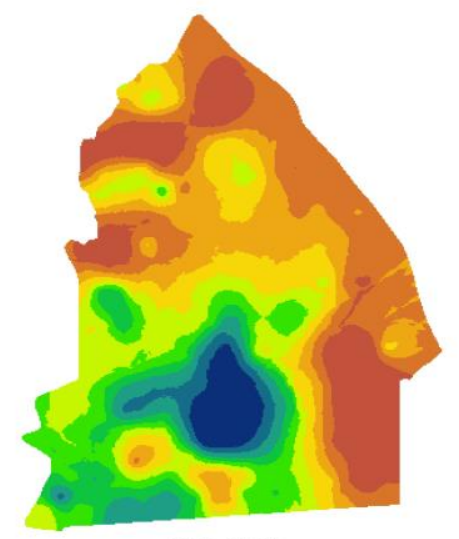

1990 SOM

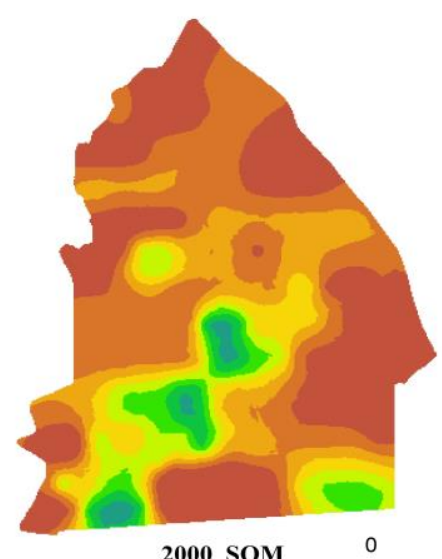

2000 SOM

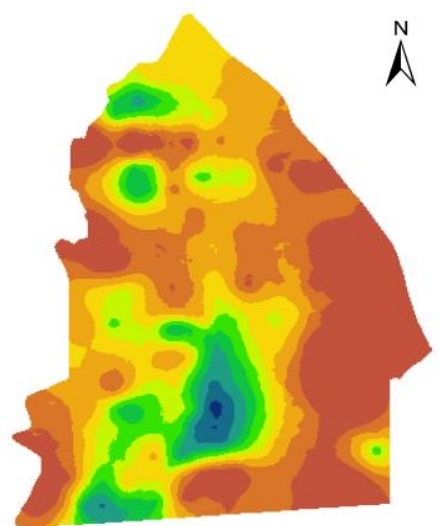

1994 SOM

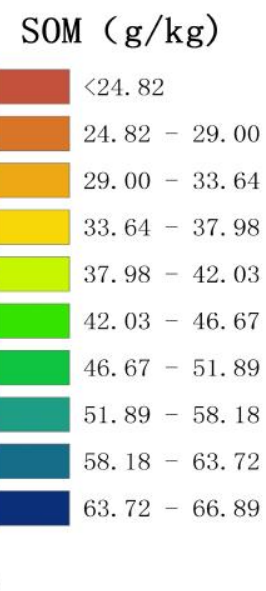

Figure 3. The spatial pattern of SOM of topsoil of Sanhu Farm

The selected model of 1990 is the Exponential and that of the other two years is the Spherical. The performance of Kriging models depends on spatial autocorrelation of the topsoil organic matter. The Range (Table 3) tells the scope that spatial autocorrelation works, which is one of the principles to set samples. Distances of neighboured samples are all less than the Range value, so the Kriging models can be used reliably.

The ratio of Nugget/Partial Sill (Table 3) reveals the factors that may affect the spatial autocorrelation of the SOM distribution. When the ratio is smaller than 0.25 , the spatial autocorrelation of the SOM distribution is very strong and the SOM distribution is mainly controlled by structural factors such as climate, soil parent material, landform, 
etc. When the ratio is bigger than 0.75 , the random factors affect the SOM distribution more, such as fertilization, cropping pattern, etc. According to Table 3, the SOM spatial pattern of 1990 and 2000 were more decided by the structural factors, while that of 1994 was more decided by random factors.

Considering the area of Sanhu farm is only $64 \mathrm{~km}^{2}$, the climate type does not change and its influence on the distribution of SOM can be omitted. So for the Suhan Farm area, we think that the landform and the soil parent material are key structural factors for SOM distribution. Meanwhile, Sanhu lake was a lake formed by low-lying land where the Yangtze river and its tributaries are found (He, 2002). The soil parent material changes with the distance from the center of the lake to the rivers. When the sample site is nearer to the center of the lake, the soil parent material has more clays; when it is nearer to the rivers, the soil parent material has more sands. In another words, the soil parent material is quite uniform with the height of the study area. On the other hand, the random factors in the Sanhu Farm area related to human activities, among which the cropping pattern was the key factor to influence the SOM spatial pattern.

Table 3. Parameters of semivariogram fitted to SOM distribution patterns

\begin{tabular}{c|c|c|c|c|c}
\hline Year & Model & Nugget & Partial Sill & Range & Nugget/Partial Sill \\
\hline 1990 & Exponential & 0.312 & 1.651 & 3577.776 & 0.189 \\
1994 & Spherical & 0.973 & 1.118 & 2161.201 & 0.870 \\
2000 & Spherical & 0.082 & 0.628 & 2150.335 & 0.131 \\
\hline
\end{tabular}

\section{Driving factors of the SOM spatial pattern changes}

Both structural and random factors affect the SOM spatial patterns. The SOM spatial pattern and its change are controlled by the mixture of the two types of factors. Table 3 shows that the SOM spatial patterns of 1990 and 2000 are affected more by the structural factors while that of 1994 is affected more by random factors. We think the elevation is the key structural factor and the cropping system is the key random factor.

The SOM Spatial Patterns of the study area have been controlled by the microlandform constantly. This area was reclaimed through a lake, the Sanhu Lake. It was formed by the extraction of lake water to the Main Canals, so the study area basically kept the landform of the Sanhu Lake. The elevation of study area is between from $25.1 \mathrm{~m}$ to $29.3 \mathrm{~m}$ (Fig. 4). Most of this area has a height of around $26-27 \mathrm{~m}$. The center part of the former lake was lowest with the richest deposit of peats, a rich source of SOM. That's why there is always a high SOM value at the center (Fig. 3).

When the relation between the SOM values and the elevation was analyzed (Fig. 5), it was found that the SOM values in the three survey years all had a strong negative correlation with the height. In the other words, in different survey years, between the elevation and the SOM value, there showed a similar pattern in which the SOM values decreased as the height increased, though every survey year's decreasing gradient was slightly different. The decreasing gradient of 1990 was 0.2656 ; that of 1994, 0.2574; that of 2000, 0.3263. The SOM values of 2000 decreased with the decrease of height more rapidly than that of the other two survey years. Though the decreasing gradient of 1990 was quite similar to that of 1994, the value of 1994 was the smallest.

The SOM values of samples with their corresponding heights were used to make a scatter diagram (Fig. 6). The diagram clearly shows the pattern of the changes of the $\mathrm{SOM}$ values during different periods after the land reclamation and intensive tillage. 
The red triangles in Fig. 6 represent the SOM values of 1990, blue 1994 and green 2000. It is important to note that the highest SOM value is not just for the site with the lowest height. Rather, the mean value of SOM decreased constantly along the three survey years (Table 4). Compared to the SOM values of the three survey years, the data from 1994 had the highest standard deviation (Table 4) and the biggest ratio of Nugget/Partial Sill (Table 3), which was affected more by human activities.

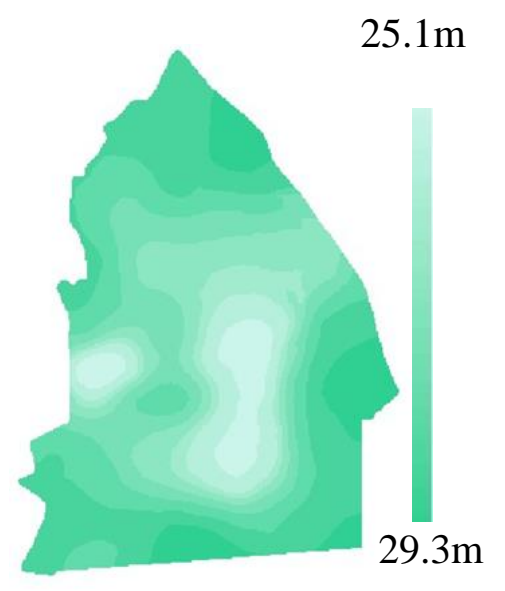

Figure 4. The DEM of study area

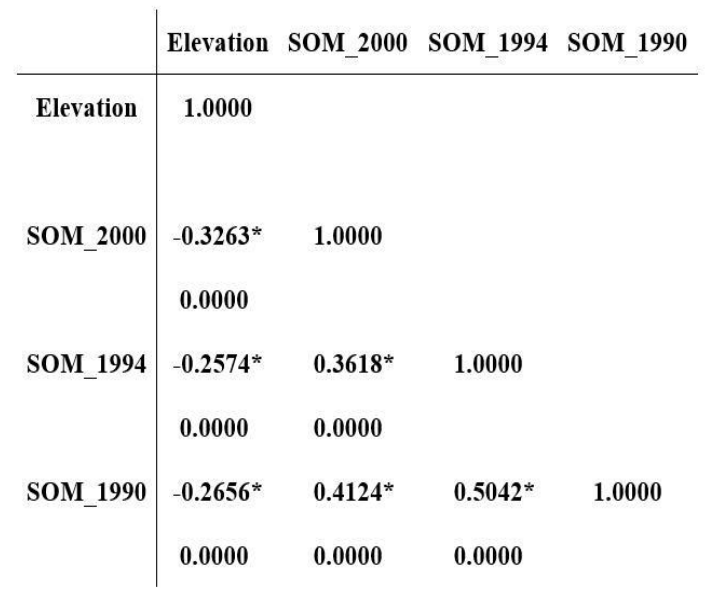

Figure 5. Relationship of SOM concentration and elevation

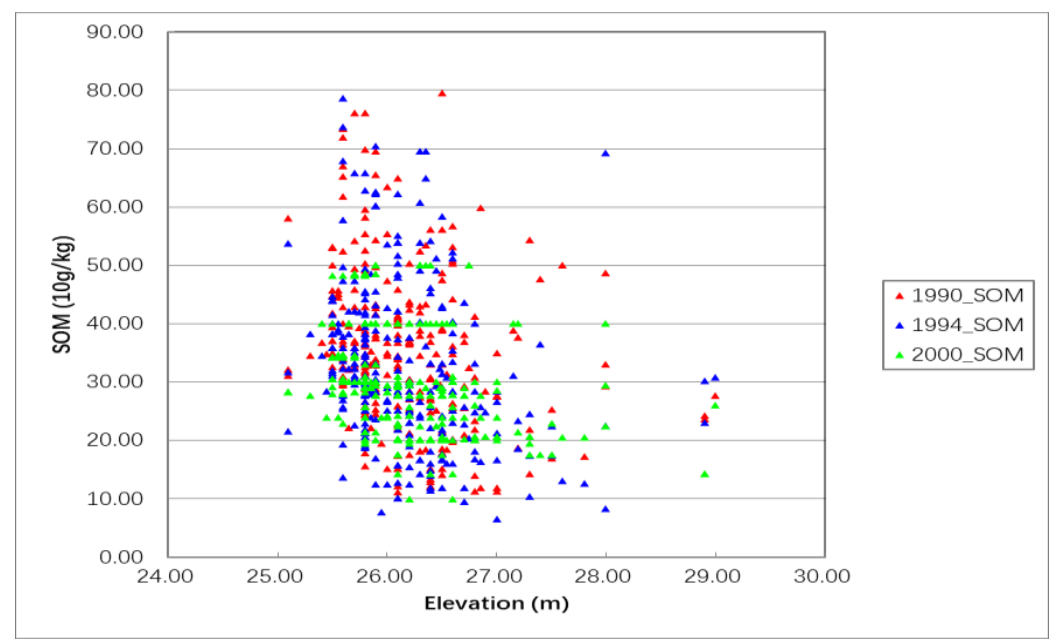

Figure 6. Relationship between elevation \& SOM concentration of every survey year

When the cropping system and its changes were considered (Fig. 7), the cause of the speciality of the SOM spatial pattern from1994 can be identified. From 1980 to 1990, the paddy land accounted for $56.35 \%$ of the total arable land and the dry land accounted for $43.65 \%$ (Fig. 7a). By then early rice and late rice were planted in rotation in paddy land while the dry land was rotated by wheat, rapeseed and soybean. But from 1991 onward, China assigned cotton production responsibility nationally and the government supplied loans with low or free interest to encourage cotton planting. Additionally, the 
price of cotton rose $10 \%$ in 1993 and continued to rise in 1994. This policy had strongly affected the cropping system of Sanhu Farm. The paddy land changed to dry land for cotton planting continuously in 1991. Until 1995, almost all paddy land was changed to dry land, where the paddy land accounted for $4.18 \%$ of the total arable land, and the dry land accounted for $95.82 \%$ (Fig. $7 b$ ). The cropping system had been cotton and rapeseed in rotation from then. In 1998, however, the price of cotton depreciated significantly, and the government reformed the circulation system of cotton the following year. Cotton was no more the nationally critical materials, and the risk of cotton planting was no longer the joint responsibility of government and peasants (Sun, 2005). But the cropping system of Sanhu Farm had changed very little for the degeneration of irrigation system guaranteed the rice production till 2008 we did our last field investigation to the area.

Table 4. The classical statistical features of SOM concentration data of Sanhu Farm

\begin{tabular}{c|c|c|c|c|c|c}
\hline Year & $\begin{array}{c}\text { Sample } \\
\text { Number }\end{array}$ & $\begin{array}{c}\text { Mean } \\
(\mathbf{g} / \mathbf{k g})\end{array}$ & $\begin{array}{c}\text { Standard } \\
\text { deviation }\end{array}$ & $\begin{array}{c}\text { Coefficient of } \\
\text { variation }(\boldsymbol{\%})\end{array}$ & $\begin{array}{c}\text { Maximum } \\
(\mathbf{g} / \mathbf{k g})\end{array}$ & $\begin{array}{c}\text { Minimum } \\
(\mathbf{g} / \mathbf{k g})\end{array}$ \\
\hline 1990 & 262 & 35.45 & 13.38 & 0.38 & 79.50 & 11.10 \\
1994 & 262 & 32.92 & 14.36 & 0.44 & 78.70 & 6.50 \\
2000 & 262 & 29.42 & 8.59 & 0.29 & 50.00 & 10.00 \\
\hline
\end{tabular}

So 1994, a period of cropping system change emerged, which is why the ratio of Nugget/Partial Sill of SOM spatial pattern was very high (Table 3). We may suppose that, when the cropping system was steady and uniform, the micro-landform was the key controlling factor of the SOM spatial pattern of Sanhu farm. But as the cropping system changed, the influence of human activity can't be neglected for the SOM distribution. Regardless of whether the cropping system was steady, the amount of SOM decreased continuously after reclamation and intensive cultivation.

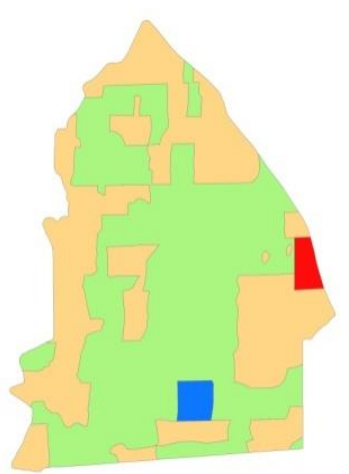

a. Land use of 1980

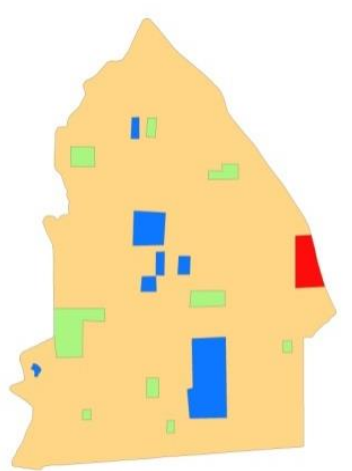

b. Land use of 2005
Legend

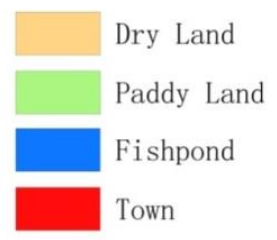

Figure 7. Land use pattern of Sanhu Farm

\section{Discussion}

Our research concerns two significant issues of the soil science domain.

The first issue is to ascertain the influencing factors and their influences on soil quality (Cambardella et al., 2004; Karlen et al., 2013a; Ontl et al., 2015) or carbon accounting (Ratayake et al., 2016). 
Many researchers suggest that soil quality is influenced by inherent (such as parent material, climate, and topography) and anthropogenic (such as tillage and crop rotation) factors (Karlen et al., 1998; Schwanghart et al., 2011). Research teams from the USDA mainly focus on changes in soil quality indicators through long-term care or maintenance of the plots for elaborately designed tests of tillage operations over several decades (Cambardella et al., 2004; Karlen et al., 2013b). Karlen et al. (2013b) verified their hypothesis that long-term moldboard plowing would have the greatest negative effect on soil quality indicators, and they put forth that less aggressive tillage systems or cropping systems could significantly improve soil quality/health. Cambardella et al. (2004) found that soil quality degradation with tillage depends upon landscape position, suggesting that soil quality increases on the backslope, and that shoulder landform elements are responsible for higher watershed-scale soil quality in the ridge-tilled watershed. Ontl et al. (2015) analyzed the influence of different bioenergy cropping systems on soil aggregation and particulate organic matter. The result showed that root system properties of crops and soil texture influenced the shift of iPOM-C concurrently, and cropping system effects were not consistent among positions across landscape.

SOM is a very important indicator of soil quality (Cambardella et al., 2004). We emphasized spatial patterns and temporal change of SOM with sampling data from three different years, while the USDA observed changes in many indicator variables of soil quality among positions across landscape, or under different cropping systems and tillage types, by comparing soil layered sampling data from a single year. They elaborately designed different scenarios of cropping systems and tillage types on different plots which was helpful to get the oriented results, but we analyzed a realworld cropping system altered by the farmers' wills, and concomitantly affected by both the market and policy. Our study area Sanhu Farm was virgin land before the reclamations of the 1960s, so it supplied a nice perspective to observe the impact of anthropogenic factors. In a spatial visual style, our research supported the hypothesis that soil quality is influenced by inherent and anthropogenic factors.

In another aspect, previous researches on carbon counting achieved some creative results. Rice cropping under waterlogged conditions enhances the soil organic matter (SOM) accumulation (Lal, 2002; Ratnayake et al., 2016). Wu (2011) reported that SOC accumulation in paddy ecosystems was faster and more pronounced than in other arable ecosystems. Kölbl et al. (2014) found that lower lands with water logging get greater accumulation of SOC in soil. Ratnayake et al. (2016) went further to find that different upland crops make limited contribution to carbon accumulation, while rice fields in the lower land landscape exhibit greater potential to store SOC in terms of carbon sequestration compared with upland cropping systems. Our research results were in accord with theirs. Furthermore, we found that the upland cropping systems also generate a smaller standard deviation.

Another issue is on the spatial modelling of SOM (SOC) and model accuracy (Miller et al., 2016; Ratnayake et al., 2016), which mainly focus on sampling density, efficiency, and the simulating precision of models. Previous research designed the rules for model selection which were used in our research in the preceding introduction, and the average distance of sample sites was about $350 \mathrm{~m}$, which satisfied the sampling distance need $(>2150 \mathrm{~m}$ ) of every model (Table 3). Kriging models we used for simulating the spatial-temporal change of SOM rely on spatial autocorrelation, which perform best when the distance between points is minimized and only appropriate to use for making predictions between points, and they are considered inappropriate for 
extrapolating beyond the extent of sampling points (Miller et al., 2016). So, near the boundary of Sanhu Farm the simulating error of SOM is relatively higher than the remaining area for there is no sample outside of the boundary. The biggest advantage of the Kriging technique over many classical statistical procedures is that it incorporates the spatial correlation of the data. Considering the sampling rule of different years was the same, and we mainly cared about the change of SOM, and the boundary area was quite limited, so we did not discuss the possible error of the boundary area in our calculation.

\section{Conclusion}

SOM plays a very important role both to condition soil properties and to mitigate climate change. Sanhu Farm with an area of $64 \mathrm{~km}^{2}$, which was a lake before the $1960 \mathrm{~s}$, was used as our study site to observe SOM variability after intensive tillage of the virgin land. Based on 262 topsoil survey samples of 1990, 1994 and 2000 respectively, the SOM spatial distribution pattern, as well as the temporal change of SOM content of the corresponding years, were analyzed.

The SOM content successively decreased with the increase of the land exploitation history. From 1990 to 2000, the sample numbers of SOM grade in Abundant had decreased from $28.6 \%$ to $19.5 \%$; the SOM grade in Poor decreased from $12.2 \%$ to 7.3\%; but the Medium grade increased from 59.2\% to $73.7 \%$. We depicted the topsoil SOM distribution maps of the three survey years with an appliance of a same legend of 10 classes divided by Natural Breaks rule under ArcGIS 10 (Fig. 7). Compared with the map of 1990, the distribution area of the top grade shrank greatly by 1994 , and the top two grades were disappeared by 2000. there was an overall tendency for the maximum or minimum value of SOM to approach to the average value over time.

The altitude of Sanhu Farm thus played a controlling role throughout the three survey years. The SOM concentration of each survey year was negatively and significantly (at 5 percent level) correlated with the elevation. The topsoil SOM distribution of the three survey years showed a similar spatial pattern whereby the highest SOM concentration value grade was distributed in the center, and the SOM value decreased incrementally as the distance to the center increased, which showed the SOM values were negratively correlated to the altitude of study area.

SOM concentration changes were influenced by crop systems changes which were affected crop prices and related policies. In particular, the crop system change from rice to cotton influenced the decrease of SOM significantly.

Acknowledgements. The work was funded by NSFC (NO. 41571487 \& NO. 40771088). Many thanks to David W. Knight for the language editing to the manuscript, who is assistant Professor of Department of Human Dimensions of Natural Resources, Colorado State University.

\section{REFERENCES}

[1] Abdollahi, L., Schjønning, P., Elmholt, S., Munkholm, L. J. (2014): The effects of organic matter application and intensive tillage and traffic on soil structure formation and stability. - Soil and Tillage Research 136: 28-37. 
[2] Abdullah, A. S. (2014): Minimum tillage and residue management increase soil water content, soil organic matter and canola seed yield and seed oil content in the semiarid areas of Northern Iraq. - Soil and Tillage Research 144: 150-155.

[3] Barrett, C. B., Bevis, L. E. M. (2015): The self-reinforcing feedback between low soil fertility and chronic poverty. - Nature Geoscience 8: 907-912.

[4] Batjes, N. H., Dijkshoorn, J. A. (1999): Carbon and nitrogen stocks in the soils of the Amazon Region. - Geoderma 89: 273-286.

[5] Batjes, N. H. (2016): Harmonized soil property values for broad-scale modelling (WISE30sec) with estimates of global soil carbon stocks. - Geoderma 269: 61-68.

[6] Cambardella, C. A., Moorman, T. B., Andrews, S. S., Karlen, D. L. (2004): Watershedscale assessment of soil quality in the loess hills of southwest Iowa. - Soil and Tillage Research 78: 237-247.

[7] Das, B., Nordin, R., Mazumder, A. (2008): An alternative approach to reconstructing organic matter accumulation with contrasting watershed disturbance histories from lake sediments. - Environmental Pollution 155: 117-124.

[8] Degryze, S., Six, J., Paustian, K., Morris, S. J., Paul, E. A., Merckx, R. (2004): Soil organic carbon pool changes following land-use conversions. - Global Change Biology 10: $1120-1132$.

[9] Dendoncker, N., Van Wesemael, B., Rounsevell, M. D. A., Roelandt, C., Lettens, S. (2004): Belgium's CO2 mitigation potential under improved cropland management. Agriculture, Ecosystems \& Environment 103: 101-116.

[10] Falloon, P., Smith, P., Bradley, R. I., Milne, R., Tomlinson, R. W., Viner, D., Livermore, M., Brown, T. (2006): RothCUK - a dynamic modelling system for estimating changes in soil $\mathrm{C}$ from mineral soils at 1-km resolution in the UK. - Soil Use and Management 22: 274-288.

[11] Gerzabek, M. H., Staunton, S. (2005): Editorial. - Journal of Environmental Radioactivity 81: 115-116.

[12] Gmach, M. R., Dias, B. O., Silva, C. A., Nóbrega, J. C. A., Lustosa-Filho, J. F., SiqueiraNeto, M. (2018): Soil organic matter dynamics and land-use change on Oxisols in the Cerrado, Brazil. - Geoderma Regional 14: e00178.

[13] He, B. (2002): The origin types and their characteristics of the lakes in Jianghan Plain. Journal of central China normal university (natural science) 36: 241-244.

[14] Karlen, D. L., Kumar, A., Kanwar, R. S., Cambardella, C. A., Colvin, T. S. (1998): Tillage system effects on 15 -year carbon-based and simulated $\mathrm{N}$ budgets in a tile-drained Iowa field. - Soil \& Tillage Research 48: 155-165.

[15] Karlen, D. L., Cambardella, C. A., Kovar, J. L., Colvin, T. S. (2013a): Soil quality response to long-term tillage and crop rotation practices. - Soil and Tillage Research 133: 54-64.

[16] Karlen, D. L., Kovar, J. L., Cambardella, C. A., Colvin, T. S. (2013b): Thirty-year tillage effects on crop yield and soil fertility indicators. - Soil and Tillage Research 130: 24-41.

[17] Kölbl, A., Schad, P., Jahn, R., Amelung, W., Bannert, A., Cao, Z. H., Fiedler, S., Kalbitz, K., Lehndorff, E., Müller-Niggemann, C., Schloter, M., Schwark, L., Vogelsang, V., Wissing, L., Kögel-Knabner, I. (2014): Accelerated soil formation due to paddy management on marshlands (Zhejiang Province, China). - Geoderma 228-229: 67-89.

[18] Kukuļs, I., Kḷaviņš, M., Nikodemus, O., Kasparinskis, R., Brūmelis, G. (2019): Changes in soil organic matter and soil humic substances following the afforestation of former agricultural lands in the boreal-nemoral ecotone (Latvia). - Geoderma Regional 15: $\mathrm{e} 00213$.

[19] Laik, R. (2004): Soil Carbon Sequestration Impacts on Global Climate Change and Food Security. - Science 304: 1623-1627.

[20] Laik, R., Kumar, K., Das, D. K., Chaturvedi, O. P. (2009): Labile soil organic matter pools in a calciorthent after 18 years of afforestation by different plantations. - Applied Soil Ecology 42: 71-78. 
[21] Lal, R. (2002): Soil carbon dynamics in cropland and rangeland. - Environmrntal Pollution 116: 353-362.

[22] Lettens, S., Van Orshoven, J., Van Wesemael, B., Muys, B. (2004a): Soil organic and inorganic carbon contents of landscape units in Belgium derived using data from 1950 to 1970. - Soil Use and Management 20: 40-47.

[23] Lettens, S., Van Orshoven, J., Van Wesemael, B., Perrin, D., Roelandt, C. (2004b): The inventory-based approach for prediction of SOC change following land use change. Biotechnologie, Agronomie, Societe et Environnement 8: 141-146.

[24] Manlay, R., Feller, C., Swift, M. J. (2007): Historical evolution of soil organic matter concepts and their relationships with the fertility and sustainability of cropping systems. Agriculture, Ecosystems and Environment 119: 217-233.

[25] Miller, B. A., Koszinski, S., Hierold, W., Rogasik, H., Schröder, B., Van Oost, K., Wehrhan, M., Sommer, M. (2016): Towards mapping soil carbon landscapes: Issues of sampling scale and transferability. - Soil and Tillage Research 156: 194-208.

[26] Mirzaee, S., Ghorbani-Dashtaki, S., Mohammadi, J., Asadi, H., Asadzadeh, F. (2016): Spatial variability of soil organic matter using remote sensing dats. - Catena 145: 118127.

[27] Nadi, M., Golchin, A., Sedaghati, E., Shafie, S., Hosseini fard, S. J., Füleky, G. (2017): Using Nuclear Magnetic Resonance $1 \mathrm{H}$ and $13 \mathrm{C}$ in soil organic matter covered by forest. - Journal of Water and Soil Science 21: 83-92.

[28] Ontl, T. A., Cambardella, C. A., Schulte, L. A., Kolka, R. K. (2015): Factors influencing soil aggregation and particulate organic matter responses to bioenergy crops across a topographic gradient. - Geoderma 255-256: 1-11.

[29] Osman, K. T. (2013): Soils: Principles, Properties and Management. - Springer Science + Business Media Dordrecht.

[30] Papienik, S. K., Lindstrom, M. J., Schumacher, T. E., Schumcher, J. A., Malo, D. D., Lobb, D. A. (2007): Charaterization of soil profiles in a landscape affected by long-term tillage. - Soil \& Tillage Research 93: 335-345.

[31] Pulleman, M. M., Bouma, J., Van Essen, E. A., Meijles, E. W. (2000): Soil organic matter content as a function of different land use history. - Soil Science Society of America Journal 64: 689-693.

[32] Ratnayake, R. R., Karunaratne, S. B., Lessels, J. S., Yogenthiran, N., Rajapaksha, R. P. S. K., Gnanavelrajah, N. (2016): Digital soil mapping of organic carbon concentration in paddy growing soils of Northern Sri Lanka. - Geoderma Regional 7: 167-176.

[33] Schulp, C. J. E., Nabuurs, G., Verburg, P. H. (2008a): Future carbon sequestration in Europe-Effects of land use change. - Agriculture, Ecosystems \& Environment 127: 251-264.

[34] Schulp, C. J. E., Veldkamp, A. (2008b): Long-term landscape - land use interactions as explaining factor for soil organic matter variability in Dutch agricultural landscapes. Geoderma 146: 457-465.

[35] Schwanghart, W., Jarmer, T. (2011): Linking spatial patterns of soil organic carbon to topography - A case study from south-eastern Spain. - Geomorphology 126: 252-263.

[36] Singh, R. J., Deshwal, J. S., Sharma, N. K., Ghosh, B. N., Bhattacharyya, R. (2019): Effects of conservation tillage based agro-geo-textiles on resource conservation in sloping croplands of Indian Himalayan Region. - Soil and Tillage Research 191: 37-47.

[37] Smith, P., Powlson, D. S., Smith, J. U., Falloon, P., Coleman, K. (2000): Meeting the UK's climate change commitments: options for carbon mitigation on agricultural land. Soil Use and Management 16: 1-11.

[38] Sun, Y., Wang, H., Huang, B. (2005): Analysis on the temporal and spatial change of cotton production of Hubei province. - Journal of Hubei University (Natural Science) 27: 385-388. 
[39] Veldkamp, A., Kok, K., De Koning, G. H. J., Schoorl, J. M., Sonneveld, M. P. W., Verburg, P. H. (2001): Multi-scale system approaches in agronomic research at the landscape level. - Soil and Tillage Research 58: 129-140.

[40] Vitharana, U. W. A., Mishra, U., Mapa, R. B. (2019): National soil organic carbon estimates can improve global estimates. - Geoderma 337: 55-64.

[41] Walkley, A., Black, I. A. (1934): An examination of the degtjareff method for determining soil organic matter, and a proposed modification of the chromic acid titration method. - Soil Science 37: 29-38.

[42] Wang, H., Song, M., Xu, X., Tang, D., Ai, T. (2010): Land use pattern Diagnosis based on physical properties and vertical structures of anthrosols profiles. - The IASTED International Conference on Environmental management and Engineering. Banff, Canada.

[43] Webb, N. R. (1998): The Traditional Management of European Heathlands. - The Journal of Applied Ecology 35: 987-990.

[44] Wood, S., Tirfessa, D., Baudron, F. (2018): Soil organic matter underlies crop nutritional quality and productivity in smallholder agriculture. - Agriculture, Ecosystems and Envrinment 266: 100-108.

[45] Wu, J. (2011): Carbon accumulation in paddy ecosystems in subtropical China: evidence from landscape studies. - European Journal of Soil Science 62: 29-34. 